\title{
Ultraviolet-B radiation induces cell death in root tips and reprograms metabolism in Arabidopsis
}

\author{
P. ZHANG ${ }^{1,2 *}$, R. WANG ${ }^{2}$, Y. WANG ${ }^{1 *}$, and J. XU ${ }^{1,2}$ \\ College of Bioengineering and Biotechnology, TianShui Normal University, TianShui, \\ GanSu 741000, P.R. China ${ }^{1}$ \\ College of Horticulture, Shanxi Agricultural University, Taigu 030801, P.R. China ${ }^{2}$
}

\begin{abstract}
Ultraviolet-B (UV-B) radiation inhibits root system growth, however, the influence of UV-B radiation on the regulation of root development remains unclear. Here, we investigated the effects of UV-B radiation on root growth and metabolism in Arabidopsis using physiological, pharmacological, and transcriptome approaches. Our previous study has demonstrated that UV-B radiation depresses auxin accumulation in roots by reducing auxin biosynthesis, transport, and response. In this study, we found that UV-B radiation inhibited primary root (PR) growth by inducing root tip cell death and thereby disrupting cell division and elongation in root tips. The destructed root structure and distorted auxin flow caused by UV-B-induced root tip cell death also led to a reduced auxin accumulation in roots. Supplementation with an auxin $\alpha$-naphthylacetic acid alleviated UV-B-repressed PR growth and further supported a notion that auxin is involved in UV-Brepressed PR growth. The UV-B radiation downregulated the expression of genes encoding the enzymes or regulators of the biosyntheses and degradations of the structural constituents of cell wall and genes involved in wax, cutin, and suberin biosyntheses, thereby repressing root system growth and development. The UV-B radiation also markedly repressed photosynthesis-related gene expression in roots, a non-photosynthetic organ. Taken together, this study suggests that UV-B radiation affects root growth by inducing cell death in root tips and reprogramming metabolism in roots.
\end{abstract}

Additional key words: endogenous auxin flow, gene expression, $\alpha$-naphthylacetic acid application, primary root growth.

\section{Introduction}

Ultraviolet (UV)-B radiation is detrimental to plant growth and development (Nawkar et al. 2013). In the past fifty years, a significant decrease in stratospheric ozone led to a continuous exposure of the earth to higher dosages of UV radiation (Solomon et al. 2008). Therefore, it is necessary to study, in detail, the molecular and physiological mechanisms of UV-disturbed plant growth responses. Previous studies helped our understanding of UV-B perceptions, signaling, and UV-B-induced DNA damage in plant cells (Lytvyn et al. 2010, Nawkar et al. 2013). UVB-induced DNA damage, including the formation of abasic sites, the production of cyclobutane pyrimidine dimers
(CPDs), and pyrimidine (6-4) pyrimidine photoproducts (6-4PP) by formation of covalent bonds between adjacent pyrimidine residues on the DNA strand, leads to deleterious mutation and even cell death in plants (Ulm et al. 2004, Fujimori et al. 2014, Lario et al. 2014).

The regulatory pathways that respond to UV radiation trigger the production of nitric oxide (NO) and reactive oxygen species (ROS), accompanied by the activation of repair mechanisms and antioxidant enzymes (Nawkar et al. 2013). High levels of UV radiation creates conditions similar to that of the oxidative stress response that results from ROS production (Mackerness et al. 1999, Jia et al. 2009). The ROS bursts lead to the opening of mitochondrial membrane permeability transition pore, and thereby result

Submitted 2 April 2020, last revision 27 July 2020, accepted 19 August 2020.

Abbreviations: ANAC032 - NAC domain containing protein 32; bZIP60 - basic region/leucine zipper motif 60; Col-0 - Columbia-0; CYCs - cell cycle regulators cyclins; DAPI - 4,6-diamidino-2-phenylindole; DEGs - differentially expressed genes; DIN2 - dark inducible 2; GO - gene ontology; IBS1 - BABA-induced sterility 1; MYB2 - myeloblastosis domain protein 2; NAA - $\alpha$-naphthylacetic acid; PCD - programmed cell death; PI - propidium iodide; PR - primary root; ROS - reactive oxygen species; SRA - Short Read Archive; UV-B - ultraviolet-B; WOX - WUSCHEL-related homeobox.

Acknowledgements: The authors gratefully acknowledge the Central Laboratory of the Xishuangbanna Tropical Botanical Garden for providing research facilities. This work was supported by the National Key Research and Development Program of China (2016YFC0501901), the China National Natural Sciences Foundation (31772383), the Basic Research Program of Qinghai Province (2019-ZJ-7033), and the Qinghai innovation platform construction project: Qinghai Provincial Key Laboratory of Restoration Ecology of Cold Area (2017-ZJ-Y20).

*Corresponding authors; e-mails: zhangping2@xtbg.ac.cn; wangyb02@126.com 
in the release of cytochrome $c$ and the generation of more ROS, which leads to a feedback loop, amplifying the stress signal induced by the initial programmed cell death (PCD) (Reape and McCabe 2008).

The UV-B photoreceptor UVR8 signaling elicits NO generation in response to UV-B radiation (Krasylenko et al. 2012). UV-B radiation-induced NO also results in stomatal closure, limits water loss, and prevents cellular injury (Lytvyn et al. 2010, Krasylenko et al. 2012). Many studies have demonstrated that flavonoid pathway is also involved in the stress resistance to UV-B radiation in plants (Kootstra 1994, Karabourniotis et al. 1992, Santelia et al. 2008, Liu et al. 2012, Ma et al. 2016, Wan et al. $2018 b$ ). Flavonoids reduce UV-B radiation-induced lipid peroxidation and malondialdehyde (MDA) accumulation in plants, and thereby alleviating plant growth inhibition caused by UV-B radiation ( $\mathrm{Li}$ et al. 1993, Chen et al. 2001, Lud et al. 2002, Winkel-Shirley 2002, Liu et al. 2012). In general, roots grow underground and are normally protected from UV-B exposure. However, the roots sometimes appear above ground due to earthquakes, animal behaviors, or strong wind (Yokawa et al. 2016, Wan et al. 2018b). The expression of UVB-resistance 8 (UVR8) gene can be detected in roots, indicating that roots could sense UV-B radiation (Mo et al. 2015). However, the precise ways in which UV-B radiation modulates plant growth and root system architecture remains unclear.

Plant growth is regulated by root meristematic cell division potential and stem cell niche activity (Aida et al. 2004, Blilou et al. 2005, Grieneisen et al. 2007, Tian et al. 2014, Ji et al. 2015, Liu et al. 2016). The progression of mitosis of eukaryotic cells is modulated by conserved molecular mechanisms. The core cell cycle regulators cyclins (CYCs) play key roles in cell cycle progression through the form of cyclin-dependent kinase (CDK)/ CYC complexes (Wang et al. 2004, Wang and Yang 2007, Craddock et al. 2016). A total of 49 CYCs of 8 classes were identified in Arabidopsis genome, including CYCAs, CYCBs, CYCC, CYCDs, CYCH, CYCL, and CYCPs (Nafati et al. 2010, Craddock et al. 2016). Among these CYCs, A- and B-type CYCs regulate the cell cycle progression through the S-, G2- and early M-phase, while D-type CYCs regulate the cell cycle progression of G1/S phase transition (Nafati et al. 2010). The plantspecific homeobox transcription factor WUSCHELrelated homeobox $(W O X)$ gene family plays vital roles in modulating plant growth and development by controlling stem cell activity in shoot/root apical meristem and cambium (Alvarez et al. 2018, Li et al. 2019).

Stem cell identity is maintained by root quiescent center (Scheres et al. 2007, Ji et al. 2015, Santuari et al. 2016). Maintaining a normal auxin gradient in the meristem is required for normal root growth (Galinha et al. 2007, Dinneny et al. 2008, Laskowski et al. 2008, Wang et al. 2009, Zhao et al. 2014). Our recent study found that UV-B reduces auxin accumulation in Arabidopsis seedlings by downregulating the expression of genes involved in auxin biosynthesis, including abscisic acid aldehyde oxidase 3 (AAO3), cytochrome P 450 (CYP79B2), yucca 2 (YUC2), $Y U C 3$, and YUC9 (Wan et al. 2018b). The UV-B radiation also reduces the abundance of PIN-formed 2 (PIN2) and auxin resistant $1(A U X 1)$ in root tips, and thereby repressing auxin transport in roots (Wan et al. 2018b). These results suggested that UV-B represses plant growth by disrupting auxin signaling. In this study, we investigated the effects of UV-B on primary root (PR) growth and the differentially expressed genes (DEGs) in UV-B-radiated roots.

\section{Materials and methods}

Plants and growth conditions: Arabidopsis thaliana L. Columbia-0 ecotype (Col-0) seeds were surface sterilized and then sown onto a 1/2 Murashige and Skoog agar medium (pH 5.75; Sigma, St. Louis, USA) with or without $10 \mathrm{nM}$ naphthalene acetic acid (NAA). UV-B radiation was performed using a narrowband UV-B lamp (TL 20W/01$R S$ with a spectral peak at $311 \mathrm{~nm}$; Philips, Eindhoven, The Netherlands) with a cellulose diacetate to block UV-C radiation as described previously (Wan et al. 2018b). Fiveday-old Arabidopsis Col-0 seedlings were subjected to $20 \mathrm{~W} \mathrm{~m}^{-2}$ of UV-B for $2-10 \min \left(2.4-12 \mathrm{~kJ} \mathrm{~m}^{-2}\right)$, and then the seedlings were transferred to normal growth conditions (a temperature of $22^{\circ} \mathrm{C}$, a 16-h photoperiod, an irradiance of $150 \mu \mathrm{mol} \mathrm{m} \mathrm{m}^{-2} \mathrm{~s}^{-1}$, and a relative humidity of $60-70 \%$ ) for $5 \mathrm{~d}$. The meristem zone length was measured as the distance between the quiescent center to the noticeably elongated cell (the cell length is two times larger than the minimum cell length in the cortex), and the cortical cell number in this region was also counted as described by Liu et al. (2013). The elongation zone length was measured as the distance between the first noticeably elongated cell to the first visible bulge (root hair emergence) (Wan et al. 2018a).

Detection of reactive oxygen species and nitric oxide in root tips: Endogenous $\mathrm{ROS}$ and $\mathrm{NO}$ production was monitored using a ROS fluorescence probe 2',7'-dichlorofluorescin diacetate (DCF DA) (Beyotime, Shanghai, China) and an NO-specific fluorescence probe 4,5-diaminofluorescein-2 diacetate (DAF-2 DA, Beyotime) (Xu et al. 2010). After UV-B treatment for $3.6 \mathrm{~kJ} \mathrm{~m}^{-2}$, the seedlings were cultured for $15,30,60$, 120 , or $240 \mathrm{~min}$ under normal growth conditions, and then the fluorescences of ROS and NO were detected. The fluorescences were examined using a confocal laser scanning microscope (LSM710, Zeiss, Jena, Germany; excitation/emission wavelengths: $488 / 530 \mathrm{~nm}$ for ROS and 490/515 $\mathrm{nm}$ for NO).

Detection of root tip cell death: UV-B-induced cell death in roots was first detected using propidium iodide (PI) staining as described previously (Xu et al. 2010). After UV-B treatment for $3.6 \mathrm{~kJ} \mathrm{~m}^{-2}$, the seedlings were cultured for $2 \mathrm{~h}$, and then the fluorescence of PI and 4,6-diamidino -2-phenylindole (DAPI) were detected. Briefly, after the roots were immersed in PI dye (Beyotime, $3 \mathrm{mg} \mathrm{dm}^{-3}$ ) for $1 \mathrm{~min}$, the roots were washed with distilled water and then were observed using a fluorescence microscope (Axioskop, Zeiss, Jena, Germany; an excitation wavelength of 546 
$\mathrm{nm})$. For DAPI staining, the roots were incubated with DAPI dye (Sigma, $1 \mathrm{mg} \mathrm{dm}^{-3}$ ) for $10 \mathrm{~min}$, and then washed with distilled water. The roots were observed using a fluorescence microscope with UV radiation filter (Xu et al. 2010). The PI and DAPI staining was repeated three times independently.

Transcriptome data analysis: MapMan (http://mapman. gabipd.org), Clustering (http://www.omicshare.com/tools/ Home/Soft/trend) and Gene ontology $(G O)$ enrichment (http://www.omicshare.com/tools/Home/Soft/gogsea) analyses were used to analyze the root transcriptome data ( $\log 2$ fold change $\geq 1$, FDR $\leq 0.01$ ) [National Center for Biotechnology Information's Short Read Archive (NCBI SRA) under accession No SRP094914, Wan et al. 2018b].

Statistical analysis: The experiments were repeated three times and the measurements were performed on three biological replicates with three technical repetitions and 12 plants were used per treatment. The statistical analysis of the differences was carried out by Student's $t$-test or ANOVA using the Statistic package for social science.

\section{Results and discussion}

Ultraviolet-B radiation significantly inhibited PR growth in a dosage-dependent manner. As shown in Fig. $1 A$, the PR growth was inhibited by $21.5,20,53.2$, and $70 \%$ when the seedlings were irradiated with UV-B of 3.6, 6, 9.6 , and $12 \mathrm{~kJ} \mathrm{~m}^{-2}$, respectively. We found that the effect of $12 \mathrm{~kJ} \mathrm{~m}^{-2}$ is the most significant, and this dose can inhibit root growth in a short time, and does not affect seedlings survival. Two major factors affect PR growth: cell division and cell elongation in root tips (Sabatini et al. 1999, Baluška et al. 2010, Zheng et al. 2011, Ji et al. 2015, Liu et al. 2015). Previously, Wan et al. (2018a) have demonstrated that the UV-B photosensitive part can be located at roots, and UV-B photoreceptor UVR8 is also expressed in roots. Furthermore, the expression of photosynthesis-related genes has been changed, but its biological significance is still unclear. To further investigate the inhibitory effects of UV-B radiation on PR growth in detail, we measured the meristem cell number and the length of meristem and elongation zones in UV-B-radiated roots (González-García et al. 2011, Li et al. 2015). As shown in Fig. 1, UV-B

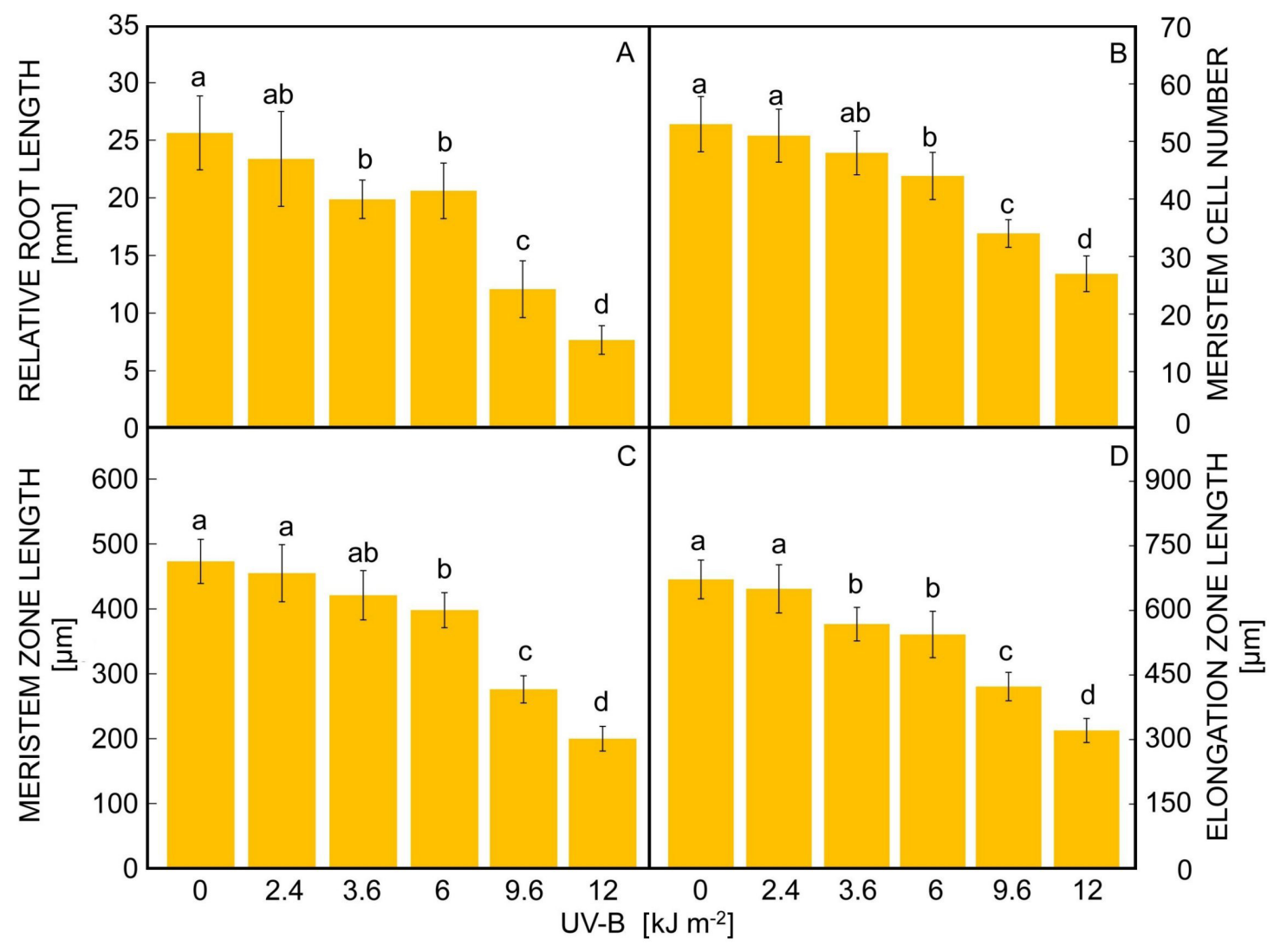

$$
\begin{array}{|c|c|c|c|}
\hline \multicolumn{2}{c}{0.5 \mathrm{~h}} & 2 \mathrm{~h} \\
\hline \text { Gene ID } & \log _{2} \mathrm{FC} & \log _{2} \mathrm{FC} & \text { Annotation } \\
\hline
\end{array}
$$

Fig. 1. Effects of ultraviolet-B (UV-B) radiation on primary root growth. Five-day-old Arabidopsis seedlings grown in a $1 / 2$ Murashige and Skoog medium were subjected to UV-B of $2.4-12 \mathrm{~kJ} \mathrm{~m}^{-2}$ and then were transferred to normal conditions. Primary root length $(A)$, meristem cell number $(B)$, meristem zone length $(C)$, and elongation zone length $(D)$ were measured after $5 \mathrm{~d}$. Means $\pm \mathrm{SEs}, n=3$ (12 plants/treatment/repeat); different letters indicate significantly different values $(P<0.05)$. $E$ - heat maps indicating $\log _{2}$ fold changes in expressions of genes involved in cell cycle and stem cell development according to the transcriptome data (see Table 1 Suppl. for the detailed gene expression). 


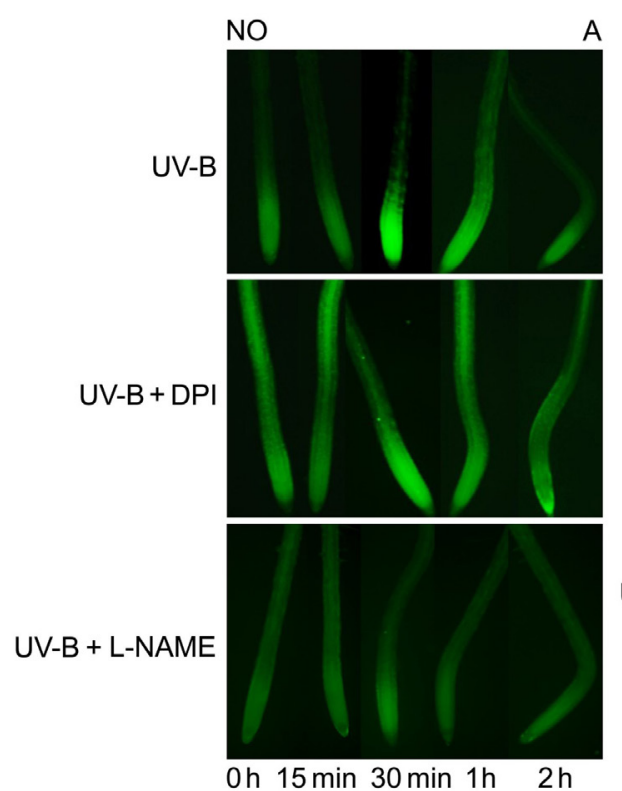

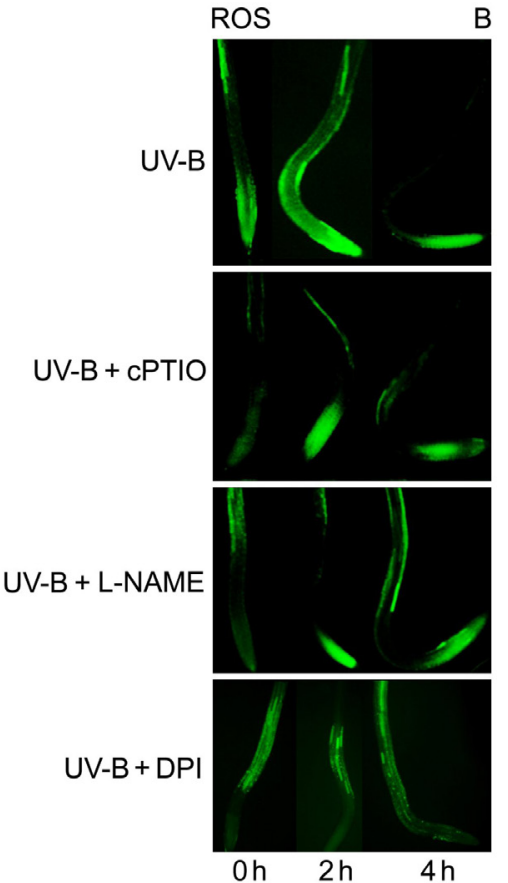

Fig. 2. A - detection of NO production in ultraviolet-B (UV-B)-treated Arabidopsis thaliana roots with or without $1 \mu \mathrm{M}$ diphenyleneiodonium chloride (DPI) and $100 \mu \mathrm{M}$ NG-nitro-L-arginine methyl ester (L-NAME) by an NO-specific fluorescence probe 4,5-diaminofluorescein-2 diacetate (DAF-2 DA). B - detection of reactive oxygen species (ROS) production in UV-B-treated Arabidopsis thaliana roots with or without $200 \mu \mathrm{M}$ 2-phenyl-4,4,5,5-tetramethylimidazoline-1-oxyl 3-oxide (cPTIO) or $100 \mu \mathrm{M}$ L-NAME, and $1 \mu \mathrm{M}$ DPI by a ROS-specific fluorescent probe 2',7'-dichlorofluorescin diacetate (DCF-DA).

radiation decreases the meristem cell number (Fig. $1 B$ ), and the length of both meristem and elongation zones (Fig. $1 C, D$ ) with the increase of radiation doses.

To further confirm the results, we investigated the differentially expressed genes (DEGs) ( $\log _{2}$ fold change $>1, \mathrm{FDR} \leq 0.01)$ by analyzing the transcriptome data of UV-B-treated Col-0 roots (NCBI SRA) under accession No. SRP094914 (Wan et al. 2018a). After irradiating with UV-B of $3.6 \mathrm{~kJ} \mathrm{~m}^{-2}$, the seedlings were transferred to normal conditions for 0.5 or $2 \mathrm{~h}$. The expression of stem cell development-related gene WUSCHEL-related homeobox 4 (WOX4) was markedly downregulated at 0.5 and $2 \mathrm{~h}$ after transfer, and the expression of three core cell cycle genes, CYCLIN D1,1 (CYCD1,1), CYCLIN P3,1 (CYCP3,1) and impaired in BABA-induced sterility 1 (IBS1), were also markedly downregulated at $2 \mathrm{~h}$ after transfer (Fig. 1E, Table 1 Suppl.). WOX4 modulates procambium differentiation in plants (Nic-Can et al. 2013). CYCD1,1 is one of core cell cycle regulators that modulates the G1/S phase transition of the cell cycle (Nafati et al. 2010). IBS1 is a core cell cycle gene encoding a cyclin-dependent kinaselike protein (Chen et al. 2010, Shamloo-Dashtpagerdi et al. 2015). These results indicated that UV-B radiation represses cell division in meristem zones by disrupting the expression of genes involved in meristematic cell division and stem cell activity in root tips, and thereby inhibiting PR growth.

Both nitric oxide (NO) accumulation and reactive oxygen species (ROS) burst can repress PR growth by inducing cell death in roots ( $\mathrm{Xu}$ et al. 2010). We thus examined the content of ROS and NO induced in UV-B- treated Col- 0 roots. As shown in Fig. $2 A, B$, UV-B radiation induces an increase in ROS and NO fluorescence, especially in root meristem zone. Supplementing the UVB-treated roots with the ROS scavenger diphenyleneiodonium chloride (DPI) significantly inhibits ROS accumulation in roots, however, it has no effect on NO content (Fig. 2A). Similarly, supplementation with either the NO synthase (NOS) inhibitor NG-nitro-L-arginine methyl ester (L-NAME) or the NO scavenger carboxy2-phenyl-4,4,5,5-tetramethylimidazoline-1-oxyl 3-oxide (cPTIO) significantly inhibit NO accumulation in roots, whereas it fails to alter ROS production compared with UV-B treatment alone (Fig. 2B). These data suggest that the UV-B-induced accumulation of $\mathrm{NO}$ and ROS might be mutually independent in the roots.

To further study the physiological basis of UV-B radiation-mediated PR growth inhibition, we next examined whether UV-B radiation-mediated PR growth inhibition is caused by cell death in roots. For this purpose, we first investigated the degree of cell death in roots using propidium iodide (PI) staining. PI is a nucleic acid dye that only can penetrate into dead or dying cells (Xu et al. 2010). UV-B radiation induces significant cell death in roots, especially in the meristem zones (Fig. 3A). The result was further confirmed by 4,6-diamidino-2-phenylindole (DAPI) staining. DAPI staining can detect the degree of the internucleosomal DNA fragmentation and the chromatin condensation caused by programmed cell death (PCD) (Chen et al. 1997). As shown in Fig. 3A, only weak DAPIpositive nuclei were detected in the untreated control roots, whereas the strong DAPI fluorescence signals were 


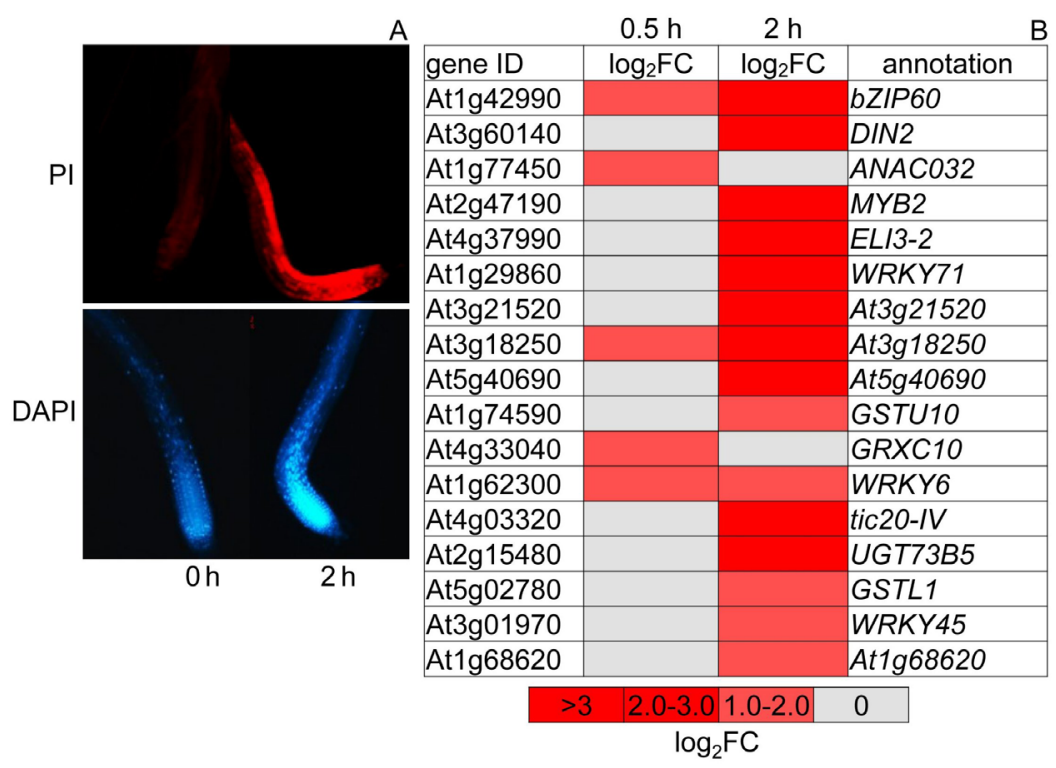

Fig. 3. Ultraviolet-B (UV-B) radiation induced cell death in root tips. $A$ - images of staining with propidium iodide (PI) and 4-diamidino2-phenylindole (DAPI) in UV-B-treated Arabidopsis thaliana roots. $B$ - heat maps indicating $\log _{2}$ fold changes in expressions of genes encoding enzymes or regulators of cell death and senescence processes according to the transcriptome data (see Table 2 Suppl. for the detailed gene expression).

detected in UV-B-treated roots from the meristem zone to the elongation zone. These results are consistent with the previous report that exposure to UV-B causes PCD in BY-2 tobacco cells (Lytvyn et al. 2010). These results indicated that UV-B radiation induces DNA damage and cell death in the root tips, especially in the meristem zones.

To further elucidate UV-B-mediated cell death in roots, we investigated the DEGs in UV-B-treated roots (Wan et al. 2018a). We found that many genes involved in cell death and senescence processes were markedly upregulated in UV-B-treated roots ( $\log _{2}$ fold change $>1$, FDR $\leq 0.01)$ (Fig. $3 B$, Table 2 Suppl.), such as three WRKY family genes WRKY6, WRKY45, and WRKY71, $N A C$ domain containing protein 32 (ANAC032), basic region/leucine zipper motif 60 (bZIP60), dark inducible 2 (DIN2), myeloblastosis domain protein 2 (MYB2), etc. Many studies have demonstrated that the plant specific WRKY transcription factors modulate plant senescence (Eulgem et al. 2000, Robatzek and Somssich 2001, 2002, Miao et al. 2004). Our previous studies indicated that overexpression of $A N A C 032$ induces $\mathrm{H}_{2} \mathrm{O}_{2}$ accumulation and age-dependent and stress-induced leaf senescence (Mahmood et al. 2016a,b, Sun et al. 2019). The bZIP60 transcription factor is involved in endoplasmic reticulum stress-induced cell death in plants (Reis and Fontes 2012). The DIN2 encodes a $\beta$-glucosidase protein that modulates senescence and necrosis caused by drought, dark, and sugar starvation (Fernández-Calvino et al. 2016). The MYB domain protein 2 (MYB2) regulates senescence by inhibiting cytokinin signaling pathway (Guo and Gan 2011). Taken together, these transcriptome data further confirmed that UV-B radiation induces DNA damage and cell death in the roots.

Auxin plays an important role in modulating PR growth and development (Jiang et al. 2003, Zhao et al. 2014).
Our recent study has demonstrated that UV-B radiation represses auxin accumulation in roots by reducing auxin biosynthesis, transport, and response (Wan et al. 2018a). The above results indicated that UV-B radiation induces cell death in root tips (Fig. 3). UV-B-induced cell death in root tips can cause the destruction of root cell structure, and thereby disturbing normal auxin flow in root tips. To further confirm the role of auxin in UV-B-mediated root growth, we examined the effect of exogenous auxin NAA on the root elongation. Addition of NAA alleviates the PR growth inhibition caused by UV-B radiation (Fig. 4A,B). These results further confirmed the role of auxin in UVB-mediated PR growth inhibition. Collectively, these results indicated that UV-B induces root tip cell death, and thereby disrupting root meristematic cell division and cell elongation. Meanwhile, the destructed root structure and distorted auxin flow caused by UV-B-induced root tip cell death also lead to reduced auxin accumulation in root tips, and finally resulting in PR growth inhibition (Fig. 4C). Gopalan (2008) reported that an immunity associated plant cell death can be reversed by auxin. The burst of ROS caused by UV-B is also the defense mechanism of oxidation system. In addition, there were studies proving that auxin plays a role in plant tolerance to arsenite-induced oxidative stress (Krishnamurthy and Rathinasabapathi 2013), so we speculated that auxin can alleviate cell death caused by oxidative damage.

To gain broader insight into UV-B-mediated plant growth, we performed an in-depth investigation of the DEGs $\left(\log _{2}\right.$ fold change $>1$, FDR $\left.\leq 0.01\right)$ by analyzing the transcriptome data of UV-B-treated Col-0 plants (Wan et al. 2018a) using Clustering trend analysis (http://www.omicshare.com/tools/Home/Soft/trend). The DEGsaresortedintothreeclustersofsimilarlyregulatedgenes $(P \leq 0.05)$, in which enriched $G O$ categories (http://www. 


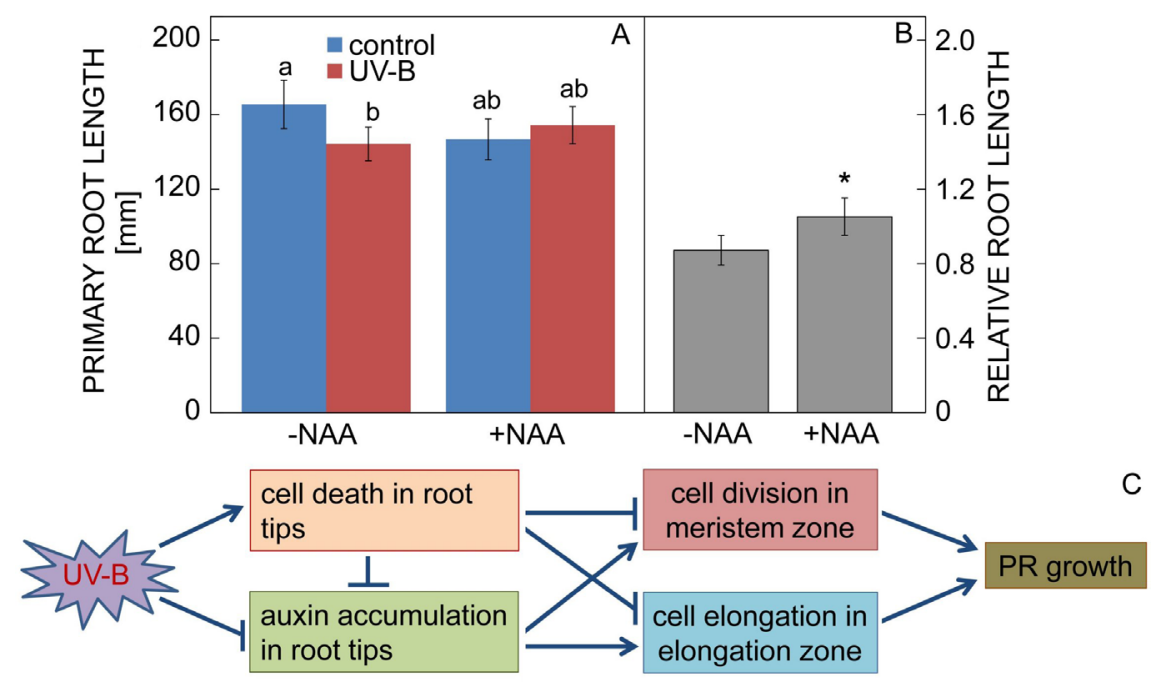

Fig. 4. Involvement of auxin in ultraviolet-B (UV-B)-repressed primary root (PR) growth. Primary root length $(A)$ and relative root length $(B)$ of UV-B-treated Arabidopsis thaliana seedlings with or without $(10 \mathrm{nM}) \alpha$-naphthylacetic acid (NAA) presented as relative to nonirradiated control values obtained using Arabidopsis thaliana seedlings. Means $\pm \mathrm{SEs}, n=3$ (12 plants/treatment/repeat); different letters indicate significantly different values (Tukey's test, $P<0.05$ ), asterisks indicate a significant difference from the control (Student's $t$-test, $P<0.05)$. $C$ - a proposed model of UV-B radiation-mediated PR growth inhibition.

omicshare.com/tools/Home/Soft/gogsea) are identified $(Q$-value $\leq 0.001)$ (Fig. 1 Suppl., Table 3 Suppl.). Under UV-B radiation, the $G O$ categories that are related to the photosynthesis and ion transport are markedly downregulated in cluster $1(\mathrm{C} 1)$ and $\mathrm{C} 2$. By contrast, $G O$ categories that are related to the response to hypoxia whose expression are upregulated after $2 \mathrm{~h}$ of UV-B radiation were specifically enriched in $\mathrm{C} 3$. These data implied that UV-B radiation modulates root responses to hypoxia stress and need to be elucidated further.

We then analyzed the DEGs involved in the biochemical or physiological processes using MapMan (http://mapman.gabipd.org). We found that the genes involved in the biosynthesis and metabolism of cell wall, lipids, glucosinolates, and terpenoids are universally downregulated in UV-B-irradiated plants (Figs. 2 Suppl., 3 Suppl., Table 4 Suppl.) indicating that UV-B radiation reprogrammed carbon metabolism and secondary metabolism in plants. Cell wall metabolism plays critical roles in modulating root growth (Keller and Lamb 1989, Showalter 1993, Hall and Cannon 2002). The cell elongation rate is closely related to the biosynthesis and degradation of the structural constituents of cell wall (Dexter 1987, Keller and Lamb 1989). In addition to cell wall metabolism, a lot of genes involved in the biosynthesis of wax, cutin, and suberin that are categorized into 'lipid metabolism' also play important roles in regulating root system architecture, such as eceriferums (CERs), glycerol-3-phosphate acyltransferases (GPATs), 3-ketoacyl-CoA synthases (KCSs), etc. (Table 4 Suppl.). Barberon et al. (2016) found that the suberization of the roots regulates the plasticity of root endodermis. Berhin et al. (2019) found that the root cap cuticle also contributes to root growth. These data suggested that UV-B-mediated metabolism reprogramming affects root system growth and development.
Second, from the metabolism overview and photosynthesis pathways, we noted that a number of genes involved in light reaction, Calvin cycle, photorespiration, and tetrapyrrole biosynthesis are downregulated by UV-B radiation, by contrast, genes involved in mitochondrial electron transport are markedly upregulated in the roots of UV-B-radiated plants (Figs. 2 Suppl., 4 Suppl.). Tetrapyrroles serve as cofactors for essential proteins involved in photosynthesis and respiration. Tetrapyrrolic metabolites also act as signaling molecules that coordinate cell organelle functions (Zhang et al. 2014). These data indicated that UV-B radiation repressed photosynthesis, whereas it promoted mitochondrial respiration. The complexes I and III of mitochondrial electronic transport chain are one of the major sites for ROS production in plants. UV-B radiation induces ROS accumulation in plants (Ulm et al. 2004, Lytvyn et al. 2010, Nawkar et al. 2013). As an adaptive feedback regulation mechanism, the upregulation of mitochondrial electron transport-related gene expression might maintain redox homeostasis in plant cells.

UV-B radiation resulted in a significant reduction of photosynthesis-related gene expression in roots, a nonphotosynthetic organ. Several studies have demonstrated that the changes in photosynthetic gene expression in roots affect root physiology (Kobayashi et al. 2013, Kang et al. 2014). Suppression of photosynthetic gene expression in roots is an adaptation regulation mechanism for plant growth under inorganic phosphate deficiency (Kang et al. 2014). However, the biological mechanisms of suppression of photosynthetic gene expression in roots remain unclear. The elevated expression of photosynthesis-related genes in roots increases $\mathrm{CO}_{2}$ fixation and improves carbon utilization in plants (Kobayashi et al. 2013). In support of this result, we found that many of genes involved in Calvin cycle and the biosynthesis and catabolism of starch and 
sucrose were generally downregulated in UV-B-treated roots. However, how the photosynthesis-related gene expression in roots regulates carbon utilization requires further elucidation.

\section{Conclusions}

Previous studies have shown that UV-B induced root bending (Wan et al. 2018a), however, the molecular mechanisms underlying UV-B-modulated root growth have not been investigated. In this study, we found that UV-B inhibited PR growth by inducing cell death in roots through the production of ROS and NO, and thereby decreasing root cell division and cell elongation. UV-B radiation-induced cell death also led to the destruction of root cell structure and subsequent distortion of auxin flow and reduced auxin accumulation in root tips, and thereby inhibiting PR growth. We also revealed that UV-B radiation-reprogrammed metabolism in Arabidopsis roots was associated with the reduction in PR growth. These findings are helpful for our understanding on UV-Bmodulated plant growth through regulation of metabolism pathways in plants.

\section{References}

Aida, M., Beis, D., Heidstra, R., Willemsen, V., Blilou, I., Galinha, C., Scheres, B.: The PLETHORA genes mediate patterning of the Arabidopsis root stem cell niche. - Cell 119: 109-120, 2004

Alvarez, J.M., Bueno, N., Cañas, R.A., Avila, C., Cánovas, F.M., Ordás, R.J.: Analysis of the WUSCHEL-related homeobox gene family in Pinus pinaster: new insights into the gene family evolution. - Plant Physiol. Biochem. 123: 304-318, 2018.

Baluška, F., Mancuso, S., Volkmann, D., Barlow, P.W.: Root apex transition zone: a signalling-response nexus in the root. - Trends Plant Sci. 15: 402-408, 2010.

Barberon, M., Vermeer, J.E.M., De Bellis, D., Wang, P., Naseer, S., Andersen, T.G., Humbel, B.M., Nawrath, C., Takano, J., Salt, D.E., Geldner, N.: Adaptation of root function by nutrient-induced plasticity of endodermal differentiation. Cell 164: 447-459, 2016.

Berhin, A., De Bellis, D., Franke, R.B., Buono, R.A., Nowack, M.K., Nawrath, C.: The root cap cuticle: a cell wall structure for seedling establishment and lateral root formation. - Cell 176: 1367-1378, 2019.

Blilou, I., Xu, J., Wildwater, M., Willemsen, V., Paponov, I., Friml, J., Heidstra, R., Aida, M., Pamle, K., Scheres, B.: The PIN auxin efflux facilitator network controls growth and patterning in Arabidopsis roots. - Nature 433: 39-44, 2005.

Chen, C.S., Mrksich, M., Huang, S., Whitesides, G.M., Ingber, D.E.: Geometric control of cell life and death. - Science 276: 1425-1428, 1997.

Chen, T., An, L., Feng, H., Yang, J., Wang, X.: The effect of UV-B radiation on membrane lipid peroxidation and mechanisms in broad bean leaves. - Acta ecol. sin. 21: 579-583, 2001.

Chen, Y., Hoehenwarter, W., Weckwerth, W.: Comparative analysis of phytohormone-responsive phosphoproteins in Arabidopsis thaliana using $\mathrm{TiO}_{2}$-phosphopeptide enrichment and mass accuracy precursor alignment. - Plant J. 63: 1-17,
2010.

Craddock, C.P., Adams, N., Kroon, J.T.M., Bryant, F.M., Hussey, P.J., Kurup, S., Eastmond, P.J.: Cyclin-dependent kinase activity enhances phosphatidylcholine biosynthesis in Arabidopsis by repressing phosphatidic acid phosphohydrolase activity. - Plant J. 89: 3-14, 2016.

Dexter, A.R.: Mechanics of root growth. - Plant Soil 98: 303-312, 1987.

Dinneny, J.R., Benfey, P.N.: Plant stem cell niches: standing the test of time. - Cell 132: 553-557, 2008.

Eulgem, T., Rushton, P.J., Robatzek, S., Somssich, I.E.: The WRKY superfamily of plant transcription factors. - Trends Plant Sci. 5: 199-206, 2000.

Fernández-Calvino, L., Guzmán-Benito, I., Del Toro, F.J., Donaire, L., Castro-Sanz, A.B., Ruíz-Ferrer, V., Llave, C.: Activation of senescence-associated dark-inducible (DIN) genes during infection contributes to enhanced susceptibility to plant viruses. - Mol. Plant Pathol. 17: 3-15, 2016.

Fujimori, N., Suzuki, N., Nakajima, Y., Suzuki, S.: Plant DNAdamage repair/toleration 100 protein repairs UV-B-induced DNA damage. - DNA Repair 21: 171-176, 2014.

Galinha, C., Hofhuis, H., Luijten, M., Willemsen, V., Blilou, I., Heidstra, R., Scheres, B.: PLETHORA proteins as dosedependent master regulators of Arabidopsis root development. - Nature 449: 1053-1057, 2007.

González-García, M.P., Vilarrasa-Blasi, J., Zhiponova, M., Divol, F., Mora-García, S., Russinova, E., Caño-Delgado, A.I.: Brassinosteroids control meristem size by promoting cell cycle progression in Arabidopsis roots. - Development 138: 849-859, 2011.

Gopalan, S.: Reversal of an immunity associated plant cell death program by the growth regulator auxin. - BMC Res. Notes 1: 126-126, 2008.

Grieneisen, V.A., Xu, J., Marée, A.F., Hogeweg, P., Scheres, B.: Auxin transport is sufficient to generate a maximum and gradient guiding root growth. - Nature 449: 1008-1013, 2007.

Guo, Y., Gan, S.: AtMYB2 regulates whole plant senescence by inhibiting cytokinin-mediated branching at late stages of development in Arabidopsis. - Plant Physiol. 156: 1612-1619, 2011.

Hall, Q., Cannon, M.C.: The cell wall hydroxyproline-rich glycoprotein RSH is essential for normal embryo development in Arabidopsis. - Plant Cell 14: 1161-1172, 2002.

Ji, H., Wang, S., Li, K., Szakonyi, D., Koncz, C., Li, X.: PRL1 modulates root stem cell niche activity and meristem size through WOX5 and PLTs in Arabidopsis. - Plant J. 81: 399$412,2015$.

Jia, X., Ren, L., Chen, Q.J., Li, R., Tang, G.: UV-B-responsive microRNAs in Populus tremula. - J. Plant Physiol. 166: 20462057, 2009.

Jiang, K., Meng, Y.L., Feldman, L.J.: Quiescent center formation in maize roots is associated with an auxin-regulated oxidizing environment. - Development 130: 1429-1438, 2003.

Kang, J., Yu, H., Tian, C., Zhou, W., Li, C., Jiao, Y., Liu, D.: Suppression of photosynthetic gene expression in roots is required for sustained root growth under phosphate deficiency. - Plant Physiol. 165: 1156-1170, 2014.

Karabourniotis, G., Papadopoulos, K., Papamarkou, M., Manetas, Y.: Ultraviolet-B radiation absorbing capacity of leaf hairs. Physiol. Plant. 86: 414-418, 1992.

Keller, B., Lamb, C.J.: Specific expression of a novel cell wall hydroxyproline-rich glycoprotein gene in lateral root initiation. - Genes Dev. 3: 1639-1646, 1989.

Kobayashi, K., Sasaki, D., Noguchi, K., Fujinuma, D., Komatsu, H., Kobayashi, M., Wada, H.: Photosynthesis of root chloroplasts developed in Arabidopsis lines overexpressing 
GOLDEN2-LIKE transcription factors. - Plant Cell Physiol. 54: 1365-1377, 2013.

Kootstra, A.: Protection from UV-B-induced DNA damage by flavonoids. - Plant mol. Biol. 26: 771-774, 1994.

Krasylenko, Y.A., Yemets, A.I., Blume, Y.B.: Cytoskeletonmediated signalling pathways in UV-B perception by plant cell. - Emir. J. Food Agr. 24: 557-564, 2012.

Krishnamurthy, A., Rathinasabapathi, B.: Auxin and its transport play a role in plant tolerance to arsenite-induced oxidative stress in Arabidopsis thaliana. - Plant Cell Environ. 36: 1838$1849,2013$.

Lario, L.D., Botta, P., Casati, P., Spampinato, C.P.: Role of AtMSH7 in UV-B-induced DNA damage recognition and recombination. - J. exp. Bot. 66: 3019-3026, 2014.

Laskowski, M., Grieneisen, V.A., Hofhuis, H., Hove, C.A., Hogeweg, P., Marée, A.F.M., Scheres, B.: Root system architecture from coupling cell shape to auxin transport. PLoS Biol. 6: e307, 2008.

Li, J., Ou-Lee, T.M., Raba, R., Amundson, R.G., Last, R.L.: Arabidopsis flavonoid mutants are hypersensitive to UV-B irradiation. - Plant Cell 5: 171-179, 1993.

Li, J., Zhao, Y., Chu, H., Wang, L., Fu, Y., Liu, P., Upadhyaya, N., Chen, C., Mou, T., Feng, Y., Kumar, P., Xu, J.: Shoebox modulates root meristem size in rice through dose-dependent effects of gibberellins on cell elongation and proliferation. PLoS Genet. 11: e1005464, 2015.

Li, M., Wang, R., Liu, Z., Wu, X., Wang, J.: Genome-wide identification and analysis of the WUSCHEL-related homeobox (WOX) gene family in allotetraploid Brassica napus reveals changes in WOX genes during polyploidization. - BMC Genomics 20: 317, 2019.

Liu, M., Cao, B., Zhou, S., Liu, Y.: Responses of the flavonoid pathway to UV-B radiation stress and the correlation with the lipid antioxidant characteristics in the desert plant Caryopteris mongolica. - Acta ecol. sin. 32: 150-155, 2012.

Liu, W., Li, R.J., Han, T.T., Cai, W., Fu, Z.W., Lu, Y.T.: Salt stress reduces root meristem size by nitric oxide-mediated modulation of auxin accumulation and signaling in Arabidopsis. - Plant Physiol. 168: 343-356, 2015.

Liu, Y., Lai, N., Gao, K., Chen, F., Yuan, L., Mi, G.: Ammonium inhibits primary root growth by reducing the length of meristem and elongation zone and decreasing elemental expansion rate in the root apex in Arabidopsis thaliana. PLoS ONE 8: e61031, 2013.

Liu, Y., Wang, R., Zhang, P., Chen, Q., Luo, Q., Zhu, Y., Xu, J.: The nitrification inhibitor methyl 3-(4-hydroxyphenyl) propionate modulates root development by interfering with auxin signaling via the NO/ROS pathway. - Plant Physiol. 171: 1686-1703, 2016.

Lud, D., Moerdijk, T.C.W., Van de Poll, W.H., Buma, A.G.J., Huiskes, A.H.L.: DNA damage and photosynthesis in antarctic and arctic Sanionia uncinata (Hedw.) Loeske under ambient and enhanced levels of UV-B radiation. - Plant Cell Environ. 25: 1579-1589, 2002.

Lytvyn, D.I., Yemets, A.I., Blume, Y.B.: UV-B overexposure induces programmed cell death in a BY-2 tobacco cell line. Environ. exp. Bot. 68: 51-57, 2010.

Ma, C.H., Chu, J.Z., Shi, X.F., Liu, C.Q., Yao, X.Q.: Effects of enhanced UV-B radiation on the nutritional and active ingredient contents during the floral development of medicinal Chrysanthemum. - J. Photochem. Photobiol. B 158: 228-234, 2016.

Mackerness, S., Surplus, S.L., Blake, P., John, C.F., BuchananWollaston, V., Jordan, B.R., Thomas, B.: UV-B induced stress and changes in gene expression in Arabidopsis thaliana: Role of signaling pathways controlled by jasmonic acid, ethylene and reactive oxygen species. - Plant Cell Environ. 22: 1413 1423, 1999.

Mahmood, K., El-Kereamy, A., Kim, S.H., Nambara, E., Rothstein, S.J.: ANAC032 positively regulates age-dependent and stress-induced senescence in Arabidopsis thaliana. - Plant Cell Physiol. 57: 2029-2046, 2016a.

Mahmood, K., Xu, Z., El-Kereamy, A., Casaretto, J.A., Rothstein, S.J.: The Arabidopsis transcription factor ANAC032 represses anthocyanin biosynthesis in response to high sucrose and oxidative and abiotic stresses. - Front. Plant Sci. 7: 1548, $2016 \mathrm{~b}$.

Miao, Y., Laun, T., Zimmermann, P., Zentgraf, U.: Targets of the WRKY53 transcription factor and its role during leaf senescence in Arabidopsis. - Plant mol. Biol. 55: 853-867, 2004.

Mo, M., Yokawa, K., Wan, Y., Baluška, F.: How and why do root apices sense light under the soil surface? - Front. Plant Sci. 6: $775,2015$.

Nafati, M., Frangne, N., Hernould, M., Chevalier, C., Gévaudant, F.: Functional characterization of the tomato cyclin-dependent kinase inhibitor SIKRP1 domains involved in protein-protein interactions. - New Phytol. 188: 136-149, 2010.

Nawkar, G., Maibam, P., Park, J., Sahi, V., Lee, S., Kang, C.: UV-induced cell death in plants. - Int. J. mol. Sci. 14: 1608$1628,2013$.

Nic-Can, G.I., López-Torres, A., Barredo-Pool, F., Wrobel, K., Loyola-Vargas, V.M., Rojas-Herrera, R., De-la-Peña, C.: New insights into somatic embryogenesis: $L E A F Y$ COTYLEDON1, BABY BOOM1 and WUSCHEL-RELATED HOMEOBOX4 are epigenetically regulated in Coffea canephora. - PLoS ONE 8: e72160, 2013.

Reape, T.J., McCabe, P.F.: Apoptotic-like programmed cell death in plants. - New Phytol. 180: 13-26, 2008.

Reis, P.A., Fontes, E.P.: N-rich protein (NRP)-mediated cell death signaling: a new branch of the ER stress response with implications for plant biotechnology. - Plant Signaling Behav. 7: 628-632, 2012.

Robatzek, S., Somssich, I.E.: A new member of the Arabidopsis WRKY transcription factor family, AtWRKY6, is associated with both senescence and defense-related processes. - Plant J. 28: 123-133, 2001.

Robatzek, S., Somssich, I.E.: Targets of AtWRKY6 regulation during plant senescence and pathogen defense. - Genes Dev. 16: 1139-1149, 2002.

Sabatini, S., Beis, D., Wolkenfelt, H., Murfett, J., Guilfoyle, T., Malamy, J., Benfey, P., Leyser, O., Bechtold, N., Weisbeek, P.: An auxin-dependent distal organizer of pattern and polarity in the Arabidopsis root. - Cell 99: 463-472, 1999.

Santelia, D., Henrichs, S., Vincenzetti, V., Sauer, M., Bigler, L., Klein, M., Bailly, A., Lee, Y., Friml, J., Geisler, M., Martinoia, E.: Flavonoids redirect PIN-mediated polar auxin fluxes during root gravitropic responses. - J. biol. Chem. 283: 31218-31226, 2008.

Santuari, L., Sanchez-Perez, G.F., Luijten, M., Rutjens, B., Terpstra, I., Berke, L., Gorte, M., Prasad, K., Bao, D., Timmermans-Hereijgers, J.L.P.M., Maeo, K.: The PLETHORA gene regulatory network guides growth and cell differentiation in Arabidopsis roots. - Plant Cell 28: 29372951, 2016.

Scheres, B.: Stem-cell niches: nursery rhymes across kingdoms. - Nat. Rev. mol. cell. Biol. 8: 345-354, 2007.

Shamloo-Dashtpagerdi, R., Razi, H., Ebrahimie, E.: Mining expressed sequence tags of rapeseed (Brassica napus L.) to predict the drought responsive regulatory network. - Physiol. mol. Biol. Plants 21: 329-340, 2015.

Showalter, A.M.: Structure and function of plant cell wall 
proteins. - Plant Cell 5: 9, 1993.

Solomon, K.R.: Effects of ozone depletion and UV-B radiation on humans and the environment. - Atmos. Ocean. 46: 185202, 2008 .

Sun, L., Zhang, P., Wang, R., Wan, J., Ju, Q., Rothstein, S.J., Xu, J.: The SNAC-A transcription factor ANAC032 reprograms metabolism in Arabidopsis. - Plant Cell Physiol. 60: 9991010, 2019.

Tian, H., Jia, Y., Niu, T., Yu, Q., Ding, Z.: The key players of the primary root growth and development also function in lateral roots in Arabidopsis. - Plant Cell Rep. 33: 745-753, 2014.

Ulm, R., Baumann, A., Oravecz, A., Máté, Z., Ádám, É., Oakeley, E.J., Schafer, E., Nagy, F.: Genome-wide analysis of gene expression reveals function of the bZIP transcription factor HY5 in the UV-B response of Arabidopsis. - Proc. nat. Acad. Sci. USA 101: 1397-1402, 2004.

Wan, J., Zhang, P., Sun, L., Li, S., Wang, R., Zhou, H., Wang, W., $\mathrm{Xu}, \mathrm{J}$.: Involvement of reactive oxygen species and auxin in serotonin-induced inhibition of primary root elongation. - J. Plant Physiol. 229: 89-99, 2018a.

Wan, J., Zhang, P., Wang, R., Sun, L., Wang, W., Zhou, H., Xu, J.: UV-B radiation induces root bending through the flavonoidmediated auxin pathway in Arabidopsis. - Front. Plant Sci. 9: 618, 2018 b.

Wang, G., Kong, H., Sun, Y., Zhang, X., Zhang, W., Altman, N., Depamphilis, C.W., Ma, H.: Genome-wide analysis of the cyclin family in Arabidopsis and comparative phylogenetic analysis of plant cyclin-like proteins. - Plant Physiol. 135: 1084-1099, 2004.
Wang, Y., Li, K., Li, X.: Auxin redistribution modulates plastic development of root system architecture under salt stress in Arabidopsis thaliana. - J. Plant Physiol. 166: 1637-1645, 2009.

Wang, Y., Yang, M.: In silico identification of co-transcribed core cell cycle regulators and transcription factors in Arabidopsis. - J. integr. Plant Biol. 49: 1253-1260, 2007.

Winkel-Shirley, B.: Biosynthesis of flavonoids and effects of stress. - Curr. Opin. Plant Biol. 5: 218-223, 2002.

Xu, J., Yin, H., Li, Y., Liu, X.: Nitric oxide is associated with long-term zinc tolerance in Solanum nigrum. - Plant Physiol. 154: 1319-1334, 2010.

Yokawa, K., Kagenishi, T., Baluška, F.: UV-B Induced generation of reactive oxygen species promotes formation of BFA induced compartments in cells of Arabidopsis root apices. Front Plant Sci. 6: 1162, 2016.

Zhang, F., Tang, W., Hedtke, B., Zhong, L., Liu, L., Peng, L., Lin, R.: Tetrapyrrole biosynthetic enzyme protoporphyrinogen IX oxidase 1 is required for plastid RNA editing. - Proc. nat. Acad. Sci. USA 111: 2023-2028, 2014.

Zhao, Q., Wu, Y., Gao, L., Ma, J., Li, C.Y., Xiang, C.B.: Sulfur nutrient availability regulates root elongation by affecting root indole-3-acetic acid levels and the stem cell niche. - J. integr. Plant Biol. 56: 1151-1163, 2014.

Zheng, B., Chen, X., McCormick, S.: The anaphasepromoting complex is a dual integrator that regulates both microRNA-mediated transcriptional regulation of cyclin B1 and degradation of cyclin B1 during Arabidopsis male gametophyte development. - Plant Cell 23: 1033-1046, 2011. 